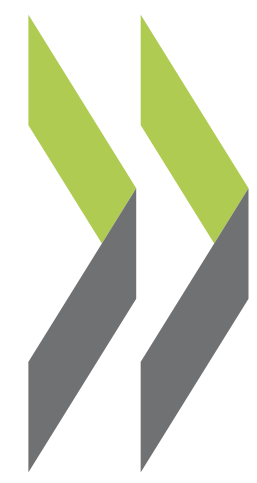

PEB Exchange, Programme on Educational Building 2001/01

\title{
School Design
}

and Management: Three

Patrick Alt

Examples from France 


\section{SCHOOL DESIGN \\ AND MANAGEMENT: \\ THREE EXAMPLES \\ FROM FRANCE}

What link can be established between successful teaching and learning, and school design? Three examples of large-scale school construction and renovation projects in France may go some way towards answering this question.

\section{School complex in Gavray, La Manche}

In 1995, the commune of Gavray in the département of La Manche started thinking of building a school complex (groupe scolaire). The school then in use consisted mostly of "prefabs" erected in the mid1960s. They had aged badly and the buildings themselves posed many safety problems. To these were added the difficulties occasioned by the distance between the school site and such premises as the canteen, gymnasium and sports grounds used by pupils every day. In order to get to these facilities, the students had to go through part of the town and cross a busy thoroughfare. A primary concern was thus to improve the children's safety.

\section{Enhancing the linkages between school cycles while avoiding school "over-population"}

After much deliberation and many meetings, in July 1997 the town council voted in favour of the project. A series of consultations was then launched, culminating with a meeting in September 1997 attended by the academy inspector, the director of departmental services in the Ministry of Education, the ministry inspector in charge of the school district, the head of the existing school complex, the college principal and numerous local politicians and parliamentary attachés. In addition to the mayor of the commune, the mayors of neighbouring towns which had children enrolled in Gavray also attended the meeting. The academy inspector immediately voiced his strong approval for the project, mainly because it would bring together on the same site the nursery and primary schools, which would then be close to the college already there. This proximity would be conducive to closer links between the various school cycles while avoiding overcrowding, each school accepting a reasonable number of pupils. The choice of the team of architects to act as prime contractor was based both on the quality of their design and

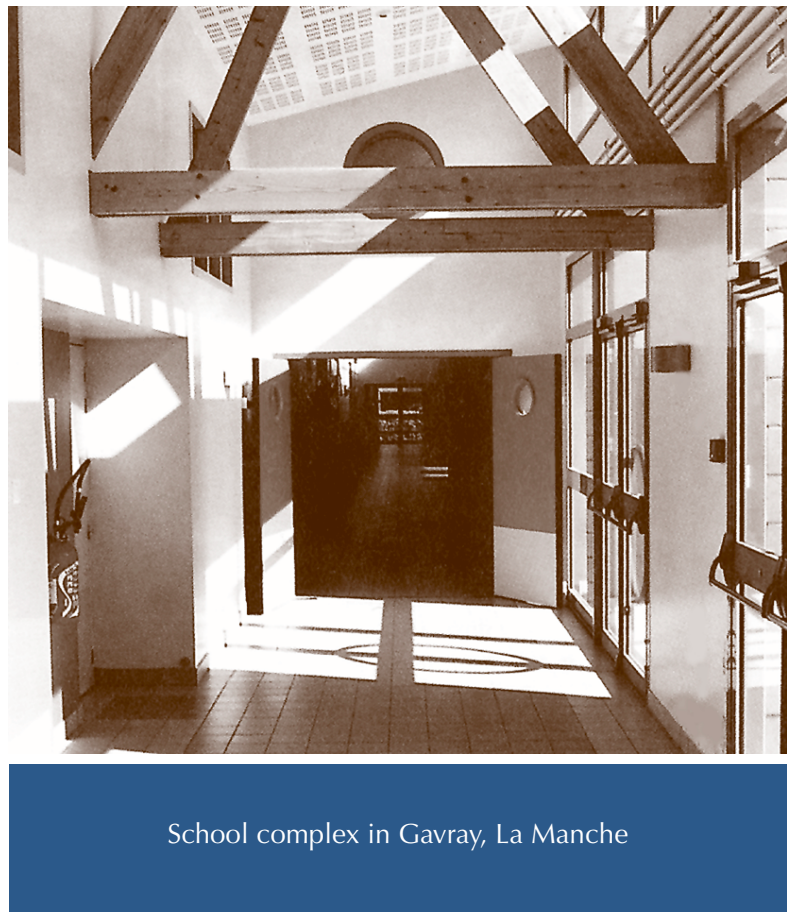

their vision of the future complex, and on its likely operating and maintenance costs.

\section{A determination to involve all the interested parties in the project}

In October 1997, a working group was set up to draft a preliminary project in collaboration with the prime contractor. The group was composed of Academy representatives, teachers, town councillors and members of the parents' association. This broad representation is worth stressing, for it shows a determination to involve all the interested parties in the project. Seven weekly meetings were needed to draw up the preliminary project. The land register was used to define needs as regards classrooms, workshops and common areas. After each meeting, minutes prepared by the prime contractor were handed out to the participants; these specified the tasks of each party before the following meeting. In January 1998, the preliminary project was completed. The mayor submitted it to the central government and departmental services. Over the next few days, the draft project was finalised and a request for funding under the Capital Equipment Allocation (dotation globale d'équipement), was lodged with the Prefecture. The state was prepared to finance half the cost of the project. After the various contractors had been consulted in April 1998, work began in September 1998. It lasted eleven months, enabling the school complex to be ready for the start of the 1999 school year. The weekly site meetings were attended not only by two deputy mayors but also by the head of the school. 
The various documents produced during the project are extremely instructive, revealing the philosophy that governed it. On page 3 of the "Presentation of the Project" drafted in December 1997, for example, a clear conviction is expressed: "In creating the school complex, the idea of involving the future users in the design process was seen as being necessary to the project's success." The first stated objective of the project is also worth stressing: "to supply a modern teaching facility in an environment that meets today's requirements regarding the hygiene and harmony needed for a child's development." The minutes of the working group's meetings are equally instructive. As from the first meeting, teachers were invited to supply a definition of "educational goals" and "principles of organisation".

\section{Pragmatic, judicious compromises}

The meetings seem to have been conducted in a very pragmatic manner. Problems were presented and explained, goals stated and possible solutions examined before any conclusion was voted upon by the town council. Parents were also closely involved. At the third meeting, for example, they were invited to submit their desiderata concerning the creation of a day-care centre.

Negotiations sometimes took place within the working group; the fourth meeting provides an example. For the nursery school, the teachers wanted the physical education rooms for the "middle" and the "big" children to be next to one another so as to rationalise the use of the staff serving the two rooms. The teachers also wanted the "motor-function gymnastics" room to be enlarged to provide storage space for equipment. The prime contractor had no objection providing that the cost remained the same. The solutions thus constituted real compromises. Putting bunks in the sleeping-room would have reduced the amount of floor space taken up. Similarly, it was planned to re-designate a passage in the room for service staff for mixed use. Study of the regulations showed, however, that bunks were not a feasible solution. It thus became clear that the distribution of space would have to be generally reconsidered, and that the presence of the service staff's representatives would therefore be very useful. The will to find collective solutions to problems led to enlarging the consultation process to include people who were not originally planned to be involved but who obviously had their place in it.

The willingness to involve all the interested parties from the outset - and a readiness to repair any omissions in the course of the process - allowed the different persons and groups to work together on the design and educational aspects of the project. It was

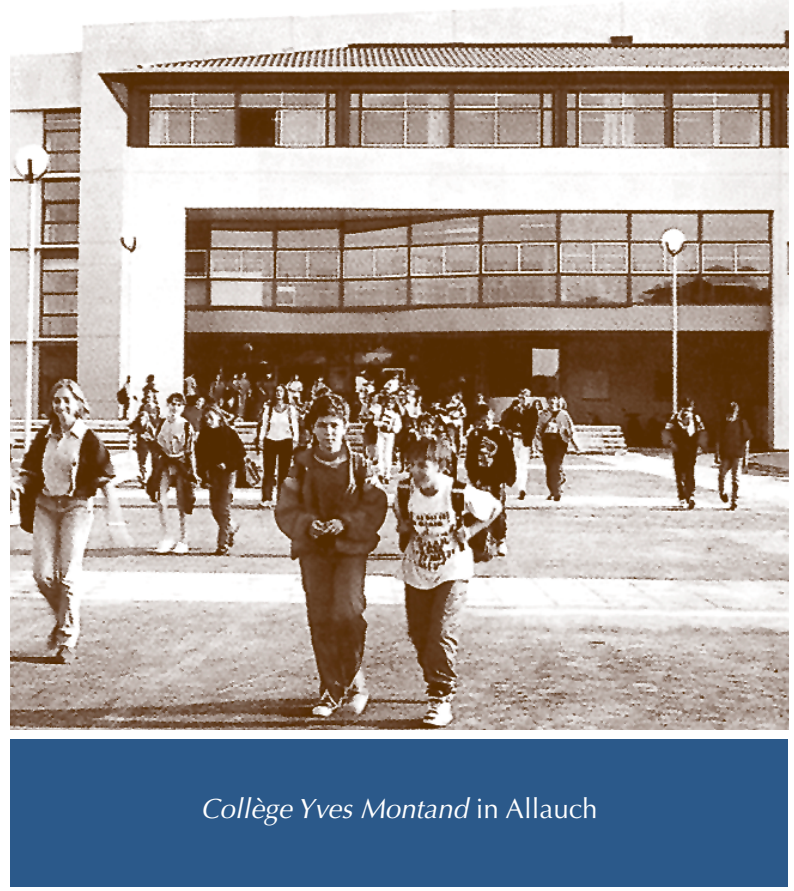

an approach that could be used again once the school was up and running.

\section{Collège Yves Montand in Allauch, near Marseilles}

\section{A design that integrates the school into its environment}

The Yves Montand lower secondary school in Allauch in the Bouches-du-Rhône opened in September 1994. Designed for 1000 pupils, the school is very large - altogether, the buildings and facilities occupy 28000 square metres spread over four storeys. Its architecture may be described as modern and sober, admitting a generous amount of light into the buildings. Classrooms are grouped by block and level: general education, language laboratories, science laboratories, technology rooms and computer centre, lecture-hall, documentation and information centre, kitchens and school restaurant, and sports facilities. They are harmoniously integrated into the pleasant surroundings of a Provençal pine wood.

\section{Premises generally well-tailored to needs, plus a successful school project}

Facilities have not been neglected: computer and video rooms, dish antennae, a server enabling parents, for instance, to consult their children's marks or the school magazine online. After six years in operation, buildings and facilities have aged quite well.

What is the quality of the teaching provided in this environment? Teaching is organised around a school 
project based on an analysis of the situation, stated objectives, the action required to achieve those objectives, monitoring and evaluation. The plan provides that full use be made of the new technology (computers, telematics, video) available. It places the documentation and information centre at the heart of the teaching and cultural project, exploiting all the resources of a modern well-designed centre. Speciallydesigned rooms are available for holding sculpture, theatre and dance workshops. Special emphasis is put on inducting and integrating 11- to 12-year-old sixth grade pupils.

The policy has paid off, since the repeat rate among sixth graders is only $2.5 \%$, compared with $11.3 \%$ for the Academy as a whole and $9.8 \%$ nationally. The rate of progression from sixth to tenth grade is $71.5 \%$ whereas the Academy and national norm is about $64.5 \%$. These performances, while not in any way exceptional, are more than respectable.

\section{Life in school}

Despite the school's closeness to the northern suburbs of Marseilles, it has not experienced any serious violence, although frictions do exist (some instances of rudeness and verbal aggression towards adults, more frequent cases of verbal and physical violence among pupils). Vandalising of buildings and equipment also occurs, but it is on the wane and happens less often than elsewhere. This good record in the matter of violence deserves emphasis, seeing that the school is attended by a very large number of pupils, almost 1 100, of whom 920 eat in during the week. The size of the site, while offering many advantages, raises problems of surveillance. Allocation of staff for this purpose is proportionate to the number of pupils enrolled; it does not usually take into account the area of the site.

By and large, the school, designed as a place to live and work, fulfils its function very well. The principal feels, however, that, despite its excellent features (environment and conditions, facilities), results could be improved, especially as regards the pass rate for the certificate of lower secondary education (brevet) $(75 \%)$ and the fall-off in academic performance observed between sixth and ninth grades (14- to 15year-old pupils).

\section{Lycée Léonard de Vinci in Levallois-Perret, in the Paris inner suburbs}

The new premises of the Lycée Léonard de Vinci were inaugurated in 1993. Nearly 1200 pupils are enrolled at this upper secondary school, in general, technical and vocational sections. The principal claims that it is the "archetype" of the $21^{\text {st }}$ century lycée since it reconciles two essential goals:
- a place for acquiring knowledge and a general, technological and vocational education;

- a place for living and forging social relations.

\section{Functional school architecture}

The teaching areas are distributed by department over two buildings and five storeys. Within each department the rooms devoted to a particular subject or speciality are grouped together. Pupils from very different sections (Diploma of Vocational Studies BEP, baccalauréat, Advanced Technician's Diploma BTS) use them regularly. An office is provided for the teachers of each subject. A computer network links these offices, the rooms set aside for pupils' activities, and the documentation and information centre. This centre is very large, occupying $600 \mathrm{~m}^{2}$ on two levels. It is equipped with small rooms where small groups of pupils can work independently. Two staff-rooms have been built. Close by, there are five work rooms and two meeting rooms. A 230-seat auditorium offers facilities for lectures, discussion meetings and entertainment. On the "living space" side, a $1000 \mathrm{~m}^{2}$ foyer offers from the outset the impression of a modern, functional and peaceful institution. Its pillars are decorated with reproductions of Leonardo da Vinci's works.

The school is exceptionally light and airy. Patios and light-wells enhance the perception of fluid pupil movement. Pupils have their own areas: two cafeterias, game rooms and relaxation rooms where extra-curricular activities can also be conducted. The ground floor contains a room set aside for the parents' associations.

\section{Creating a climate of confidence conducive to learning}

The school project is founded on the diversity of education offered (19 different examinations prepared for, from BEP to BTS) and the idea that they are all of equal value. It aims to ensure that pupils pass the BEP and then move on to the BTS. It does this successfully. It is built around two concepts: the discipline needed for the school to function harmoniously, and the dialogue required to establish a mood of mutual confidence and to build self-reliance. The school's performance is remarkable and deserves special mention. Its tenth-year pupils are slightly more socially advantaged than the national average. On the purely academic plane, however, pupils are not particularly privileged since $13.2 \%$ of them are two years behind when they enter tenth grade, compared with the national average of $6.7 \%$. It is a known fact that the chief determining factor in academic attainment at 

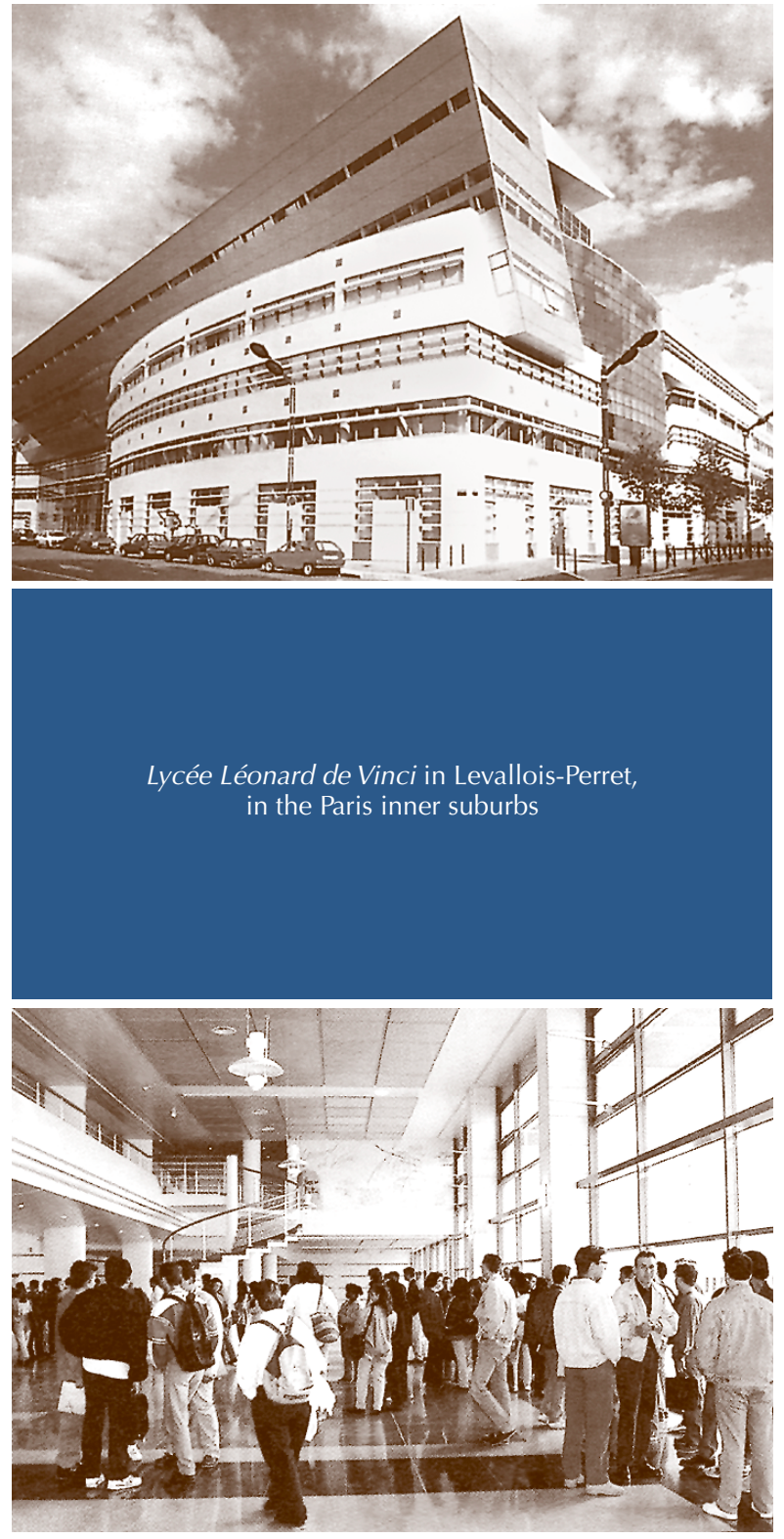

the lycée is pupil age. What exactly do the school's attainment indicators show? In the 1999 examinations, its baccalauréat success rate was $84 \%$, whereas the Academy and national norm was $78 \%$, giving it a relative added value of $7.7 \%$. Even more remarkable, the rate of progression from tenth grade to baccalauréat was $73 \%$, whereas the national norm was only $58 \%$, i.e. the school's rate was $26 \%$ higher. A final indisputable mark of the school's success is the steep increase in the number of enrolment applications from private school pupils $(17.4 \%$ of the tenth-grade pupils come from these schools).

\section{Other general considerations}

What general conclusions may be drawn from these three examples of building or renovation?

\section{The importance of preparatory work prior to building}

The importance of preparation well in advance of building cannot be over-emphasised. Many vital choices are made at the moment a project is envisaged: choice of site, refurbishing or new construction, quality of materials and broad design options which will be refined at a later stage.

The building of the school complex in Gavray is a revealing example. Four years elapsed between 1995, when the town authorities conceived the project, and September 1999, when the complex officially opened. The gestation period was long but fruitful. The methodology employed in drawing up and monitoring the project was exemplary in the sense that a working group was set up which included all the interested parties (local politicians, teaching and non-teaching staff, inspectors, parents, municipal technical services and, of course, the architect). The group had a clear working procedure. It met at regular intervals, kept minutes and assigned tasks of varying complexity to its members, the conclusions of which were examined and approved by the group before being forwarded for adoption by the town council. Over and above the specific contribution of this procedure - constitution of a widely-based group observing a strict methodology - to the building project itself, it had the merit of giving all those locally concerned by the life and running of the school the opportunity to work together in practical fashion, to reflect on the design problems posed by teaching and education and collectively to devise answers to those problems.

The problems in question do not vanish once a building is opened. They continue to arise during the running of the school, the aim of which is to ensure that every child gets the best possible education. The habit of working together according to a particular method, acquired when a school is under construction, should be able to survive when it is running normally. This is a practical embodiment of the wish expressed in the 1983 Decentralisation Act to see the different local education players - officials, administration, staff, users - taking part in school management, via school boards or councils.

\section{Taking teaching needs fully into account}

The preparatory work must meet a number of basic criteria, particularly as regards safety. It can also usefully take account of certain imperatives that have proved their value in other cases. The example of the Lycée Léonard de Vinci is worth following in this respect. Its design contains many features of special interest. The offices set aside for the teachers in each 
of the subjects taught in the school can encourage co-operation among teachers of the same subject and can be used for meetings, discussions and interdisciplinary work. The same is true of the small rooms attached to the documentation and information centre which pupils can use for working in small groups. The central location of this large, modern and userfriendly centre, which the school can use as an educational and cultural focal point, should also be emphasised. Another essential factor is that the school is well-endowed with modern facilities for information technology. These, combined with the previously mentioned facilities, should provide the material conditions conducive to guided individual study and individual pupil assistance in an upper secondary school, or cross-disciplinary work and diversified career paths in a lower secondary school. Mention should also be made of the importance of facilities such as a convivial staff-room, a spacious lecture-hall, an attractive, spacious foyer decorated with reproductions of art works, a school restaurant supplemented (in a lycée) by one or more cafeterias and places reserved for pupil activities. Finally, there should be a room close to the entrance, distinct from the visiting room, set aside for parents' meetings.

\section{Important as good design is, the school project is even more fundamental}

The collective development of an architectural project and the existence of facilities which make for easier living in general and foster innovative teaching and learning methods are extremely important, but other even more fundamental factors cannot be ignored. If we take the example of the Yves Montand school, there can be no denying the excellence of its design or the exceptional attractiveness of its site. Yet the school's size, very large for a lower secondary school (over 1000 pupils), and the difficulty in exercising permanent supervision over the whole site are a source of problems. One stems from the simple fact that, above a given number of pupils, the adults in a school, especially the administrative and teaching staff, cannot get to know all the pupils, or their families, personally. Direct human interaction is, however, partly responsible for the level of attainment by children of this age. In Allauch, the strong personal involvement of the teachers, the management and the administration has enabled - aided no doubt by the pleasant surroundings - an acceptable level of academic attainment and conviviality to be maintained.

Then there is the example of the Lycée Léonard de Vinci, whose school project manages to harness energies by defining the school as a place not only for learning but also for living and reaching out to the community. Discipline and dialogue are the school's watchwords. They respond to two needs often expressed by French high school students: security and tranquillity on the one hand, contact among themselves and with the adults in charge of them on the other hand. Both these examples clearly illustrate the need for a strong educational project as the structural backbone of the school. Good building design can undeniably contribute to such a project.

In conclusion, it should be mentioned that the Ministry of Education has for many years now appointed school principals "in advance", the better to supervise the building of a new upper or lower secondary school by the local authority. Expensive as this is, it is a clear sign of the central administration's recognition of how important design considerations are to a school's future running. These pre-appointed principals cannot be content with merely monitoring the technical side of the building operations. They must also - and most importantly - do the preparatory work for the school project, which, once the school has opened, they will devise, implement and evaluate in collaboration with all the partners, and the teaching staff in particular, and thereby offer pupils the learning environment and academic opportunities worthy of the school built for them.

\section{Article contributed by:}

\section{Patrick Alt}

Proviseur

Lycée Maximilien Vox

5, rue Madame

75006 Paris, France

Tel.: $33(0) 145497871$

Fax: 33 (0)142842410

patrick.alt@scola.ac-paris.fr

This article was also published in Administration et éducation, issue 86, the review of the French association of educational administrators (AFAE). Patrick Alt would like to thank Roger Chudeau, IA-DSDEN of La Manche, Patrick Funel, principal of Collège Yves Montand in Allauch, and Patrick Sorin, head of Lycée Léonard de Vinci in Levallois-Perret, for the information they provided. 